Edição especial - Sociedade e ambiente no Semiárido: controvérsias e abordagens

Vol. 55, p. 117-140, dez. 2020. DOI: 10.5380/dma.v55i0.73165. e-ISSN 2176-9109

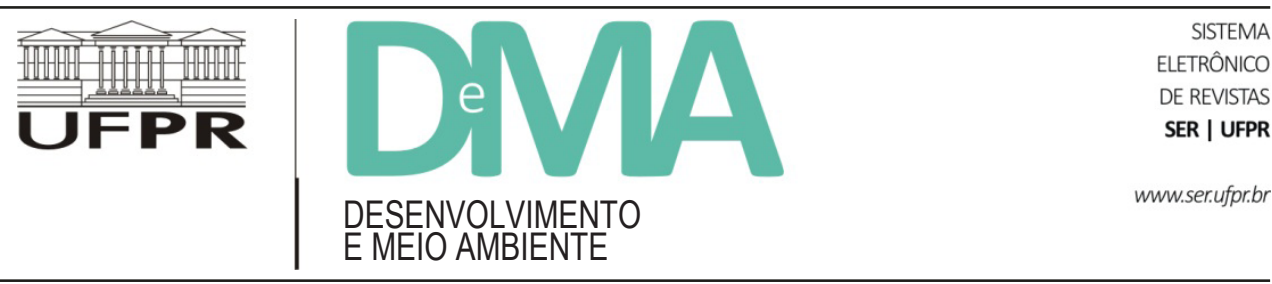

\title{
Redes sociais na gestão dos recursos hídricos do semiárido: o caso do Projeto de Integração do Rio São Francisco no Estado do Ceará
}

\section{Social networks in water resources management in the semiarid: The São Francisco River Integration Project in the State of Ceará}

\author{
Everton Nogueira SILVA ${ }^{1}$, Patrícia Verônica Pinheiro Sales LIMA²*, Maria Ivoneide Vital RODRIGUES ${ }^{3}$, \\ Ahmad Saeed KHAN², Francisco CASIMIRO FILHO ${ }^{2}$ \\ ${ }^{1}$ Universidade Estadual do Ceará, Fortaleza, CE, Brasil. \\ ${ }^{2}$ Universidade Federal do Ceará, Fortaleza, CE, Brasil. \\ ${ }^{3}$ Secretaria de Educação do Estado do Ceará, Fortaleza, CE, Brasil. \\ *E-mail de contato: pvpslima@gmail.com
}

Artigo recebido em 25 de abril de 2020, versão final aceita em 30 de agosto de 2020, publicado em 18 de dezembro de 2020.

RESUMO: O objetivo central do estudo é descrever a rede das principais entidades envolvidas nas decisões tomadas no âmbito da gestão e implementação do Projeto de Integração do Rio São Francisco (PISF). Para tanto, foi adotado um recorte que abrangeu a porção do projeto inserida no Estado do Ceará. Os dados analisados foram obtidos por meio de entrevistas. O método utilizado foi a Análise de Redes Sociais (ARS). Os principais resultados mostraram que são poucas as entidades interagindo no PISF no Estado do Ceará e estas apresentam baixa conexão. Além disso, observou-se que a gestão do projeto se dá sob baixos níveis de implementação dos princípios de boa governança. A conjuntura observada é problemática, pois implica espaço reduzido para a discussão de prioridades e competências e, portanto, uma menor probabilidade de resolução de conflitos e definição de medidas mais gerais de convivência com o semiárido.

Palavras-chave: governança; gestão hídrica; políticas públicas. 
ABSTRACT: The main objective of the study is to describe the network of the main entities involved in the decision making process within the scope of the management and implementation of the São Francisco River Integration Project (PISF). To this end, the portion of the project inserted in the State of Ceará was selected. The analyzed data were obtained throughout interviews. The method of analysis used was the Social Network Analysis (ARS). The main results showed that there are few entities interacting in the PISF in the state of Ceara and those have a low connection. In addition, it was observed that the project management takes place under low levels of principles of good governance practices. The observed situation is problematic as it implies reduced space for the discussion of priorities and competences, therefore, a lower probability of conflict resolution and definition of more general measures of how to live with the semiarid region.

Keywords: governance; water management; public policies.

\section{Introdução}

Em um cenário de mudanças climáticas, as projeções para as áreas semiáridas são pessimistas. Estudos apontam que as secas irão se intensificar e se tornar mais frequentes (Scholes, 2020), levando à escassez de alimentos e pondo em risco a segurança alimentar de milhões de pessoas. O Semiárido Brasileiro ( $\mathrm{SAB}$ ) será uma das regiões mais afetadas, com previsão de secas mais frequentes e duradouras e elevação da temperatura entre $2^{\circ} \mathrm{C}$ e $5^{\circ} \mathrm{C}$ até o final do século XXI (Marengo et al., 2018). Os impactos da concretização de tais projeções são preocupantes, haja vista que o SAB abriga mais de 27,9 milhões de habitantes (dados referentes a 2017), distribuídos em $1.128 .697 \mathrm{~km}^{2}$ que inserem 1.262 municípios localizados em dez estados brasileiros: os nove estados nordestinos e Minas Gerais. Além disso, é a região com maior proporção de pobres do Brasil (Galvão et al., 2020).

O governo brasileiro há muitos anos reconhece a necessidade de medidas para atenuar os impactos das secas no $\mathrm{SAB}$ e promover a segurança hídrica na região. Essa preocupação encontra-se explícita no documento "Uma Política de Desenvolvimento Econômico para o Nordeste", elaborado pelo Grupo de Trabalho para o Desenvolvimento Econômico do Nordeste - GTDN, o qual foi organizado com o propósito de criar uma estratégia de desenvolvimento para a região. No âmbito das mudanças climáticas, também existe uma preocupação que é percebida na Primeira e na Segunda Comunicação Nacional à UNFCCC (Convenção-Quadro das Nações Unidas sobre Mudança do Clima, ou Convenção do Clima), no Fórum Brasileiro sobre Mudanças Climáticas (FBMC), no Plano Nacional de Adaptação, assim como na Política Nacional sobre Mudanças Climáticas.

Quanto às estratégias do governo federal para a redução da vulnerabilidade às secas no $\mathrm{SAB}$, observa-se que por muitos anos houve uma preocupação em resolver o problema por meio da construção de reservatórios e grandes obras hídricas, como forma de garantir água para a população. Contudo, essa postura vem sendo substituída por intervenções voltadas para a geração de emprego e renda e redução de pobreza (Lima et al., 2016). É inconteste que os esforços governamentais provocaram mudanças positivas na região. Os impactos das secas foram atenuados (Campos, 2015), embora a insegurança hídrica ainda persista (Nasuti et al., 2013). Na prática, as estratégias adotadas pelo governo têm 
foco em medidas de mitigação (Obermaier \& Rosa, 2013). Em termos gerais, foram elaboradas a partir de premissas técnicas, com pouco estímulo à participação da população nos processos de tomada de decisão (Silva, 2018). Esse é o caso do Projeto de Integração do Rio São Francisco - PISF.

O PISF é uma proposta antiga, colocada como uma estratégia de mitigação dos impactos das secas no SAB. O projeto tem como ideia central garantir a segurança hídrica e viabilizar o desenvolvimento da região (Ferreira, 2017). Trata-se da criação de infraestruturação capaz de captar água do Rio São Francisco e distribuí-la para bacias do nordeste setentrional, mais especificamente cidades nos estados do Ceará, Paraíba, Pernambuco e Rio Grande do Norte. É um projeto de articulação político-econômica entre os governos estaduais estados receptores e estados doadores das águas para a integração - e o governo federal.

Contudo, existe uma série de pontos controversos na implementação do PISF. Há questionamentos quanto aos impactos ambientais e socioeconômicos nas áreas localizadas no entorno das obras. Existem conflitos relativos ao beneficiamento de determinados grupos econômicos, denúncias quanto ao uso irregular de recursos públicos e incongruências na elaboração e na gestão do projeto (Guimarães Jr., 2016; Ferreira, 2017; Morais et al., 2020).

Uma das fragilidades na operacionalização do projeto é a fraca articulação entre os atores envolvidos (Loureiro et al., 2014). Essa articulação adquire especial importância nesse caso, dado que a gestão integrada dos recursos hídricos, em todas as suas dimensões, é extremamente complexa e requer a abertura de espaços para discussões e reflexões profundas que auxiliem na resolução de conflitos causados principalmente por interesses divergentes (Brito, 2013).

A integração do Rio São Francisco apresenta uma complexa rede de agentes estatais e societários de tal modo que as ações propostas requerem uma interface e a troca de informações entre diferentes instituições. Todos os segmentos da sociedade devem ser ouvidos para que haja uma maior participação e apoio nos processos decisórios. A redução dos conflitos decorrentes de interesses específicos se dará por comportamentos descentralizados, organização da sociedade e existência de capital social (Maciel et al., 2014).

Rocha et al. (2018) argumentam que a água, por ser um bem essencial à vida, deve ser gerida de maneira participativa e descentralizada, prevalecendo os interesses públicos sobre quaisquer interesses privados. Por sua vez, Barbosa \& Martins Jr. (2018) reforçam que o fortalecimento de redes de sociabilidade e cooperação contribui para que haja a democratização e a efetivação de estratégias de inserção social, principalmente aquelas direcionadas às ações do Estado, não sendo diferente para a integração do rio São Francisco. Para um processo democrático e participativo, a governança se faz presente como paradigma de reconhecimento de vez e voz da sociedade nas decisões tomadas, principalmente, pelo poder público.

O conceito de governança reforça a importância das redes sociais, pois é dependente do envolvimento e da interação entre governo, sociedade civil e mercado (empresas) para que se possa criar e implementar políticas públicas voltadas para o desenvolvimento (Kapucu \& Hu, 2020). As redes sociais devem ter por princípio a compatibilização de objetivos políticos, econômicos e sociais e os 
meios para se alcançar o equilíbrio nas decisões de interesse comum (Howlett et al., 2013).

Em diversos estudos, as redes sociais são apontadas como um caminho a ser seguido para a condução da governança ambiental, pois a partir de seus princípios pode-se identificar as formas de organização que possuem a capacidade de conectar os atores que pertencem a categorias e níveis distintos, de modo a criar, como definem Bodin \& Crona (2009), estruturas flexíveis e adaptativas de governança. Além disso, a flexibilidade das redes pode favorecer a adaptação à constante evolução das problemáticas socioambientais que surgem ao longo da consecução do projeto (Mertens et al., 2005).

Na perspectiva que uma rede bem formada e articulada é fator determinante para a resolução dos muitos conflitos envolvidos na gestão do PISF, este artigo busca responder às seguintes questões: existe uma rede de articulação entre os agentes envolvidos no Projeto de Integração do Rio São Francisco? Quais os principais agentes responsáveis pela transmissão de informações e potenciais negociadores de solução de conflitos? Os princípios de boa governança estão perpassando a gestão do projeto? Para tanto, o objetivo central do estudo é descrever a rede das principais entidades envolvidas nas decisões tomadas no âmbito da gestão e da implementação do Projeto de Integração do Rio São Francisco (PISF) e entender como os princípios de governança estão contemplados. A definição da rede é uma contribuição aos gestores, pois sabe-se que uma rede social densa, que interliga atores que pertencem a diversos setores da sociedade, pode vir a favorecer a construção da distribuição equitativa de oportunidades de desenvolvimento entre atores e instituições públicas (Mertens et al., 2005).

\section{Aspectos conceituais da governança e das redes sociais como determinantes para a integração do Rio São Francisco}

Na sociedade contemporânea atual, a questão hídrica torna-se cada vez mais complexa, dado o cenário de escassez de água e a crescente demanda de usuários e seus usos múltiplos. Não se pode pensar em processos verticais de gestão para o uso do recurso ambiental água. De acordo com Silva (2018), é necessário que haja o fortalecimento do diálogo entre representantes dos poderes público e privado, por meio de canais como fóruns e câmaras setoriais e em um ambiente favorável à boa governança.

O conceito operacional da governança pode ser visto como uma forma de implementar as políticas públicas governamentais no contexto dos processos decisórios em que há participação dos diferentes atores sociais dos setores: público, privado e terceiro setor (Goria et al., 2010). Gomides \& Silva (2009, p. 178) acrescenta que uma boa governança consiste na:

[...] capacidade das sociedades humanas para se dotarem de sistemas de representação, de instituições e processos, de corpos sociais, para elas mesmas se gerirem, em um movimento voluntário. Esta capacidade de consciência (o movimento voluntário), de organização (as instituições, os corpos sociais), de conceitualização (os sistemas de representação), de adaptação a novas situações é uma característica das sociedades humanas. É um dos traços que as distinguem das outras sociedades de seres vivos, animais e vegetais.

A boa governança para o setor público é pautada em seis princípios fundamentais apresentados 
na Tabela 1. O termo "boa governança" refere-se à presença dos princípios de governança nas ações relacionadas à gestão pública; já a conceituação de "má governança" refere-se à ausência total dos mesmos.

A boa governança é colocada como uma plataforma de gestão necessária para ações de políticas públicas em que haja o envolvimento de diferentes atores nos processos decisórios. Partindo para uma discussão sobre a gestão dos recursos ambientais, as ações de decisão do poder público devem estar alinhadas às necessidades e à realidade da sociedade civil interessada. Para Garcia (2014, p. 51), a boa governança "[...] sugere uma participação conjunta e articulada de todos os setores da sociedade em torno de um propósito único e comum, que é conseguir o desenvolvimento sustentável".

No contexto da gestão dos recursos hídricos, Braun (2008) observa que há falhas nas políticas públicas para a promoção da boa governança para a água, como é o caso de alterações dos objetivos sociais mais horizontais, pois a água também é vista como um insumo produtivo. Com o debate entre os atores sociais envolvidos dentro do princípio da boa governança, os gestores tendem a criar modelos mais igualitários e sustentáveis de acesso e apropriação dos recursos hídricos por todos, não havendo exclusão de nenhuma classe social. Nota-se, portanto, que a implementação dos princípios da boa governança para a integração do Rio São Francisco requer um espaço de discussão sobre o conceito social de território. O território deve ser visto não somente como uma unidade geográfica, e sim como um espaço onde atuam forças ambíguas de criação, (des)construção e reprodução, com o objetivo de atender ou resistir aos interesses do capital (Brito, 2013), pois em ecossistemas frágeis, como o semiárido, há cada vez mais a necessidade

TABELA 1 - Princípios da boa governança para o setor público.

\begin{tabular}{|c|c|}
\hline PRINCÍPIO & SIGNIFICADO \\
\hline 01 - Voz e responsabilização & $\begin{array}{l}\text { Retrata até que ponto os cidadãos de um país são capazes de participar da escolha do } \\
\text { seu governo, bem como a liberdade de expressão, liberdade de associação e meios de } \\
\text { comunicação livres. }\end{array}$ \\
\hline 02 - Estabilidade Política & $\begin{array}{l}\text { Esse princípio de governança destaca que a natureza de uma guerra provoca a devastação } \\
\text { humana e ecológica, correspondendo ao terrorismo ambiental. Assim, é de responsabilidade } \\
\text { de todos manterem-se informados para tornarem-se conscientes dos atos praticados contra } \\
\text { a natureza. }\end{array}$ \\
\hline 04 - Qualidade Regulatória & $\begin{array}{l}\text { Consiste na captura de percepções da capacidade do governo de formular e implementar } \\
\text { políticas sólidas e regulamentos que permitam e promovam o desenvolvimento de um país. }\end{array}$ \\
\hline 05 - Estado de Direito & $\begin{array}{l}\text { É aquele no qual cada indivíduo ou potência política é submetido ao respeito ao direito, } \\
\text { tornando-se dependentes das leis promulgadas. Esse princípio captura as percepções sobre } \\
\text { o grau em que os agentes têm confiança e respeitam as regras da sociedade e a qualidade da } \\
\text { execução dos contratos, dos direitos de propriedade, da polícia e dos tribunais. }\end{array}$ \\
\hline 06 - Controle da Corrupção & $\begin{array}{l}\text { Esse princípio captura as percepções em que o poder público é exercido para ganhos } \\
\text { particulares, constatando, dessa maneira, a corrupção. }\end{array}$ \\
\hline
\end{tabular}

FONTE: Adaptado de Rogers et al. (2006) 
de se construir um conceito de sustentabilidade orientado no processo participativo e de valoração dos conhecimentos das populações locais (Serrão et al., 2020). É nesse contexto que se entende o papel de uma rede de agentes fortalecida para que o PISF seja efetivo.

Pretty (2003) observa que os processos de gestão pública fomentados por meio de redes sociais tornam-se mais efetivos do que os processos de gestão realizados apenas por instituições formais. As redes de políticas passam a ser vistas como a representação de espaços relacionais que atribuem sentido ao conteúdo estratégico e às ações individuais e coletivas de atores envolvidos em políticas de caráter público. Ao associar as redes de políticas às redes sociais, há a construção de meios relacionais em que os agentes sociais passam a se articular entre si por intensa comunicação e intercâmbio de recursos e informações para formatação e mobilização de grupos de interesses e execução de propósitos comuns (Procopiuck \& Frey, 2009).

Schultz-Jones (2009) destaca o papel das redes sociais de pequena escala, que geralmente são muito conectadas ou densas, aumentando a credibilidade necessária entre os atores para compromissos em torno de soluções cooperativas. Já as redes amplas e com conexões mais esparsas aumentam a capacidade para a troca de informações necessárias para a geração de soluções inovadoras. A estrutura mais adequada para uma rede social é aquela que leva em conta os resultados que se pretende alcançar e a fase corrente do processo de governança (ex.: início, reorganização, consolidação). As duas perspectivas apresentadas poderão indicar quais são as características estruturais mais prováveis de trazer benefícios para o alcance da ação coletiva (Bodin \& Crona, 2009).
Para a formatação das redes sociais no processo de gestão pública, se faz perceptível observar o princípio da afinidade entre os atores sociais, sendo este um requisito norteador para o surgimento de formulações de políticas públicas, pois os atores só se tornam importantes quando agem como parte integrante ou em nome de grupos de interesse (Delgado et al., 2013).

\section{Metodologia}

\section{1 Área de estudo e origem dos dados}

Dada a grande extensão coberta pelo Projeto de Integração do Rio São Francisco e fatores restritivos de renda e logística, adotou-se como recorte duas áreas referentes à implementação do projeto no Estado do Ceará, inseridas nos municípios de Jati e Penaforte. Em Jati está o reservatório previsto para receber as águas do Rio São Francisco no Ceará. Penaforte, vizinho a Jati, é o município onde serão abertas as comportas que permitirão o escoamento até o Castanhão, que é o açude que abastece a Região Metropolitana de Fortaleza. A escolha dos municípios adotou como critério o fato de concentrarem as obras da integração no Ceará, que ainda estavam em andamento no momento da pesquisa.

Entre março e dezembro de 2017 foram realizadas visitas aos dois municípios, quando foi possível colher informações por meio da aplicação de um questionário preliminar. $\mathrm{Na}$ ocasião, foram consultados representantes de órgãos públicos, agricultores assentados, agricultores familiares, representantes de sindicatos rurais e produtores rurais de médio e grande porte, com o objetivo de identificar os elementos (nós) que iriam compor a rede de atores envolvidos no PISF. 
Por se tratar de uma obra de grandes dimensões, é natural que exista uma diversidade de agentes envolvidos no Projeto de Integração do Rio São Francisco, seja na esfera pública, representada pelos governos federal (Ministério da Integração), estaduais (secretarias estaduais) e locais (prefeituras municipais), seja na esfera da sociedade civil ou terceiro setor (ONGs, associações e demais entidades civis). As visitas aos dois municípios permitiram a identificação inicial dos agentes ou principais entidades atuantes nas decisões tomadas no âmbito da gestão e da implementação do Projeto de Integração do Rio São Francisco no Ceará. Essas entidades foram selecionadas para compor uma amostra preliminar dos nós de uma rede chamada no estudo de: "Rede dos agentes atuantes no Projeto de Integração do Rio São Francisco no Ceará”. A amostra definitiva foi definida por meio de amostragem pela técnica Snowball (Bola de Neve). Foram identificadas oito principais entidades no Estado do Ceará: Comitês de Bacias Hidrográficas do Estado do Ceará (CBH), Cáritas, Federação das Associações do Perímetro Irrigado Jaguaribe-Apodi (FAPIJA), Companhia de Gestão dos Recursos Hídricos do Ceará (COGERH), Secretaria das Cidades do Estado do Ceará, Secretaria de Recursos Hídricos do Estado do Ceará e Ministério da Integração (M.I). A CODEVASF (Companhia de Desenvolvimento do Vale do São Francisco e Parnaíba), responsável pela gestão técnica da integração, também participou da pesquisa.

Além das entidades citadas, o estudo contemplou a opinião da população diretamente atingida pelas obras nos dois municípios, ou seja, a população rural. Como representantes desse último grupo, foram entrevistadas lideranças rurais. Em ambos os grupos a coleta de dados foi realizada por meio da aplicação de questionários elaborados a partir de fundamentação teórica e observações oriundas de visitas de campo. As perguntas do questionário buscaram captar informações relativas a indicadores distribuídos em seis princípios de governança: voz e responsabilização, estabilidade política, eficácia governamental, qualidade regulatória, estado de direito e controle da corrupção. No grupo das entidades, além da temática governança, o questionário também conteve perguntas que subsidiaram o cálculo dos indicadores da análise da rede, descritos a seguir na seção 3.2. É importante ressaltar que os referidos questionários foram aprovados pelo comitê de ética da Universidade Federal do Ceará sob o número: CAAE 82541817.6.0000.5054/ Parecer $\mathrm{n}^{\circ}: 2.481 .625$.

\subsection{Análise de redes}

Meinzen-Dick (2007) observa que há diferentes soluções propostas para regular as interações do ambiente humano e o recurso água, existindo uma necessidade urgente de se compreender melhor os sistemas de gestão dos recursos hídricos existentes. Assim, para se estudar a gestão para a governança da água é útil adotar uma perspectiva de rede para mapear, descrever e analisar as interações formais e informais entre as várias entidades e atores, dentre os quais: agências estatais, comunidades locais, ONGs e empresas privadas. Nessa perspectiva, a metodologia das redes foi escolhida porque permite identificar os padrões de relacionamento entre as entidades identificadas. Conhecer esses padrões é importante porque pode melhorar o fluxo de informações entre as entidades.

De acordo com Tomaél \& Marteleto (2006), o compartilhamento de informações entre os atores de 
uma rede assegura ganhos, pois reduz as incertezas, favorece parcerias e otimiza resultados. No caso do PISF, espera-se que, quanto maior a conexão entre os participantes, maior a probabilidade de solução de conflitos e maior o espaço para a discussão das prioridades e competências, evitando, por exemplo, a sobreposição de funções e a negligência.

Para a análise das redes sociais, existe uma série de conceitos-chave, tais como: A) Ator - são os indivíduos, entidades, organizações ou países objetos de estudo; B) Laço Relacional - ligação estabelecida entre par de atores; C) Díade - ligação ou relacionamento estabelecido entre dois atores; D) Tríade - conjunto de três atores e os possíveis laços entre eles; E) Subgrupo - conjunto de atores e todos os laços entre eles; F) Grupo - finito conjunto de atores definidos por critérios conceituais, teóricos ou empíricos, em que as medidas da rede são tomadas; G) Relação - coleção de laços de um tipo específico entre membros de um grupo; e H) Rede Social - conjunto finito de atores e as relações entre eles (Chaffin et al., 2016).

O conceito de "nós" refere-se aos elementos básicos que formam a estrutura de uma rede social (pontos de encontro entre indivíduos e/ou organização), as posições (estruturas de trabalho), as ligações ou vínculos (relacionamentos entre organizações e/ou pessoas) e os fluxos (troca de bens tangíveis e intangíveis). Esses assumem dimensões de coordenação técnico-produtiva (eficiência operacional e flexibilidade produtiva), coordenação interorganizacional (flexibilidade estrutural) e coordenação tecnológica (troca de informações e capacitação inovativa) (Souza et al., 2014). Lemieux \& Ouimet (2008) destacam que a análise estrutural de redes pode ser feita por meio de indicadores. Nessa pesquisa foram usados dois grupos: i) indicador densidade de relações e ii) medidas de centralidade, descritos a seguir.

\section{A) Densidade de relações}

Representa o grau de conexões existentes entre os elementos da rede. É medida por meio da expressão:

$$
\frac{L}{N(N-1) / 2}
$$

Sendo: $L=$ número de relações (conexões) entre elementos e $N=$ número de elementos (nós) dentro da rede

$\mathrm{O}$ valor da densidade varia entre 0 a 1 , sendo que o valor 1 indica que a rede apresenta 100\% dos laços possíveis. Por outro lado, valores próximos a zero indicam que a rede apresenta uma baixa conexão entre seus membros, o que pode ser prejudicial quanto ao fluxo de informações esperado entre atores de uma rede (Hatala, 2006).

B) Centralidade dos atores, relações diretas com outros atores, representando as posições mais ou menos centrais dentro da rede.

Sob o aspecto dos indicadores de redes sociais, Liu et al. (2020) percebem que o grau de centralidade passa a se constituir como uma importante métrica de análise, onde se define o poder de influência de determinados atores sob o aspecto do relacionamento com outros atores condicionados à posição estrutural em que se encontram. Sob a abordagem estrutural, Wellman \& Berkowitz (1988) observam que esta tem se mostrado uma poderosa forma de utilizar estruturas analíticas de ligações "micro" de redes interpessoais com "macroestruturas" de sistemas sociais. A centralidade de grau $(C D)$ para um ator ou nó é dada por: 


$$
C D(n i)=d(n i)
$$

Sendo: $d(n i)=$ o grau nodal de um nó; $i$ é o número de nós adjacentes a ele.

O grau nodal consiste em contar o número de arcos incidentes em um nó $i$, ou seja, o nó $i$ passa a ter seu grau de centralidade expresso em uma rede social a partir das relações desse nó com os demais integrantes da rede (Higgins \& Ribeiro, 2018). Pode variar entre 0 (quando o nó está isolado) a $g$-1, quando o nó está em contato com todos os nós da rede.

A centralidade de intermediação (caminhos entre os nós $\left(C_{B}\left(n_{i}\right)\right)$ é dada por:

$$
C_{B}\left(n_{i}\right)=\sum_{j<k} \frac{g_{j k}\left(n_{i}\right)}{g_{j k}}
$$

Sendo: $g_{j k}$ é o número de caminhos geodésicos (mais curtos e de mesmo tamanho) que ligam os nós $j$ e $k$, $g_{j k}(n i)$ é o número de caminhos geodésicos, no total de $g_{j k}$, que passa pelo nó $n i$.

As duas medidas de centralidade permitirão identificar a importância de cada nó na rede de atores que envolvem a integração do Rio São Francisco.

Por fim, a centralidade de proximidade corresponde à soma das distâncias de um vértice da rede em relação aos demais vértices do grafo da rede. Considere $G$ a notação para o grafo que representa os componentes (vértices) de uma rede de agentes e suas respectivas ligações, $n$ o número de vértices do grafo, $x$ cada um dos vértices e $d_{G}(x, i)$ a distância geodésica de $x$ a $i$. O cálculo da centralidade de proximidade é feito a partir de:

$$
\sigma_{c}(x)=\frac{1}{\sum_{i=1}^{n} d_{G}(x, i)}
$$

Os cálculos das medidas descritas foram realizados por meio do software UCINET.

\section{Resultados e discussão}

\subsection{A rede de atores envolvidos nas}

decisões tomadas no âmbito da gestão e implementação do Projeto de Integração do Rio São Francisco no Ceará

O Projeto de Integração do Rio São Francisco no Ceará tem oito principais entidades envolvidas (Tabela 2). Como já mencionado, as entidades identificadas atuam no projeto formando o que se denominou de rede de agentes da integração do São Francisco no Estado do Ceará. Para os representantes dessas entidades, há perspectiva de que o PISF promova relevantes mudanças sociais para o semiárido, principalmente aquelas relacionadas à redução da pobreza extrema. Isso porque acreditam que haverá um fluxo regular de ações que garantirão a ampliação e a melhoria no planejamento para os diferentes usos dos recursos hídricos, principalmente aqueles relacionados ao abastecimento humano. Assim, o entendimento é o da expansão do abastecimento de água para as regiões rurais do semiárido sob uma proposta sustentável e de universalização de acesso à água.

O sociograma produzido por meio da Análise de Redes Sociais (ARS) descreve a estrutura de relações entre as oito entidades (Figura 1) e outras entidades citadas por estas como parceiras nos debates sobre a integração do Rio São Francisco. Os quadrados azuis representam as entidades citadas e os círculos vermelhos a fonte das citações (no caso, as entidades pesquisadas). Como é possível observar:

- Nem todas as entidades estão conectadas entre si e há falta de reciprocidade na troca 
TABELA 2 - Entidades envolvidas no Projeto de Integração do Rio São Francisco no Ceará.

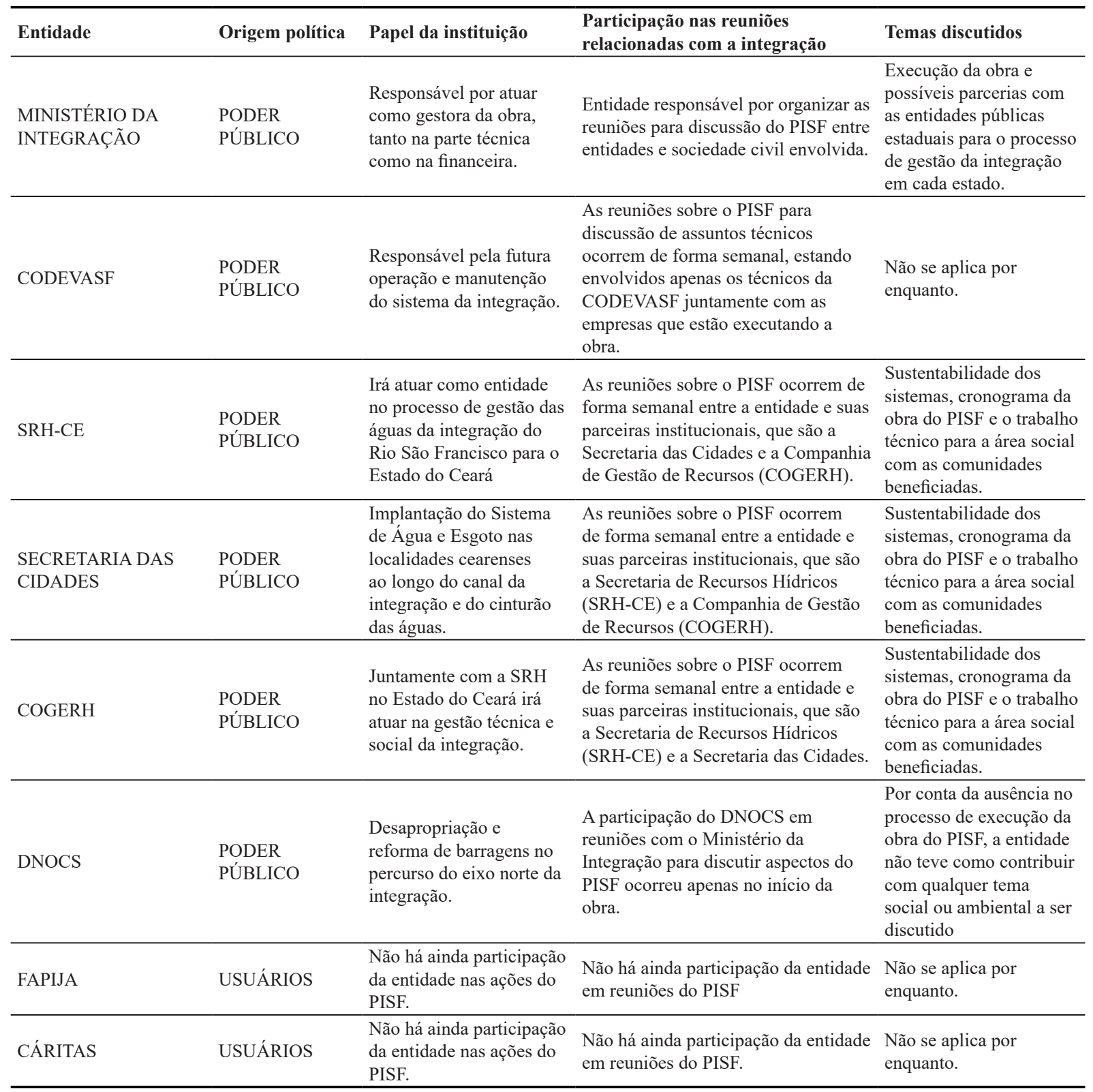

FONTE: Elaboração própria. 
de informações. Por exemplo, a Secretaria das Cidades não foi apontada como parceira por nenhuma das entidades pesquisadas, embora tenha relatado relacionar-se com o Ministério da Integração e a CAGECE;

- Há entidades citadas por mais de uma das entidades pesquisadas, o que demonstra seu potencial para intercâmbio de informações. É o caso da COGERH e do Ministério da Integração, ambos citados por quatro entidades;

- As entidades com maior potencial para propagação de informações, considerando as parcerias identificadas, são a COGERH (com 8 ligações), a CODEVASF (com 4 ligações) e a Cáritas (com 4 ligações);
- A FAPIJA e o Ministério da Integração são fracos emissores, haja vista que relataram se relacionar apenas com a COGERH. Portanto, são classificadas como entidades periféricas.

Nesse cenário, a rede de entidades envolvidas com o PISF deve ser fortalecida de tal modo a favorecer um maior fluxo de informações, um comportamento coordenado, redução de incertezas e chances de melhor resultado do projeto, bem como a participação de um número cada vez maior de atores.

As informações do sociograma podem ser complementadas com as métricas dos nós, que analisam basicamente a centralidade das entidades dentro da rede e métricas das redes, que analisam as

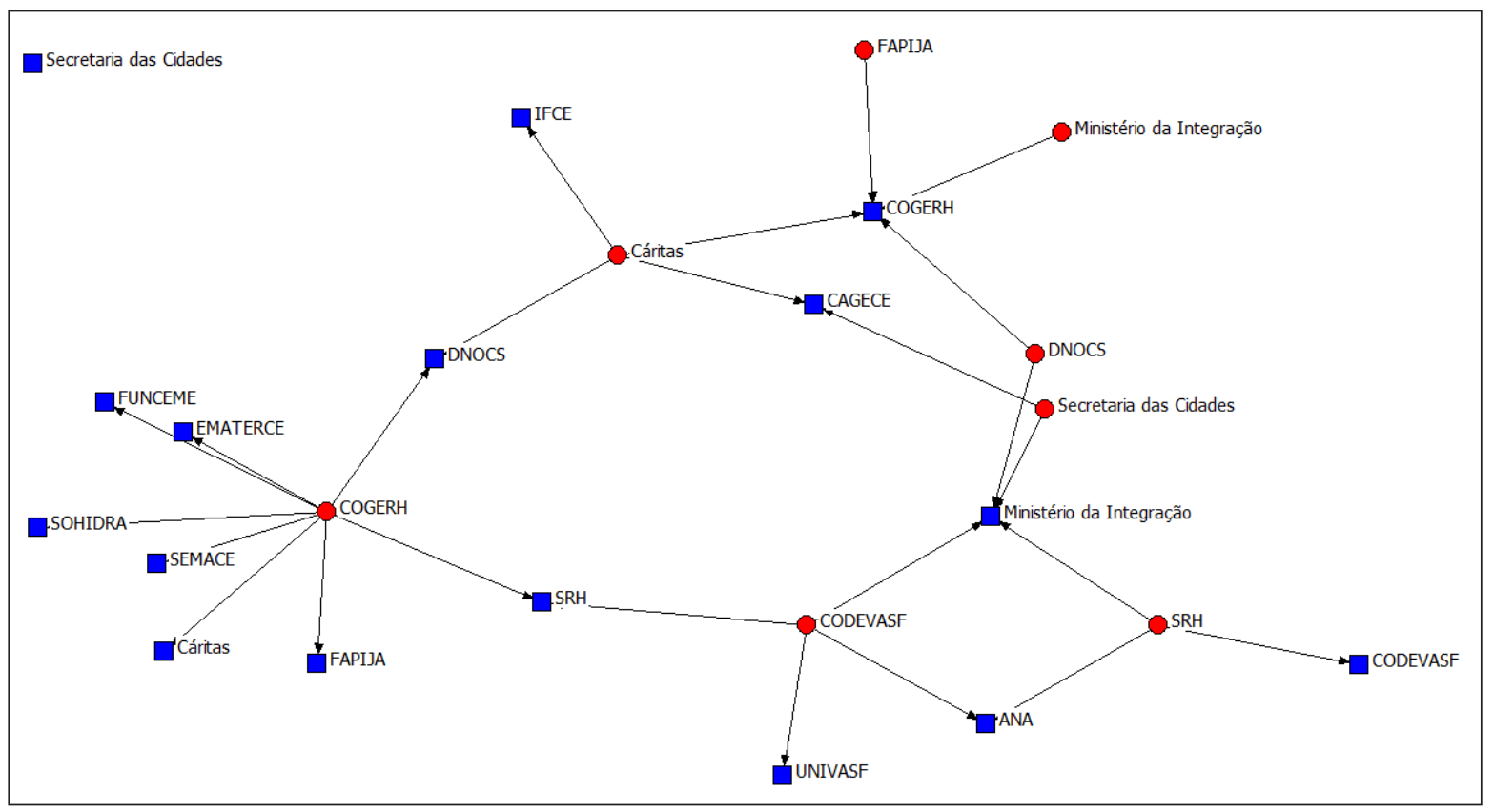

FIGURA 1 - Rede dos agentes atuantes no Projeto de Integração do Rio São Francisco no Ceará. FONTE: Elaboração própria. 
características da rede como um todo (Scott, 2013). A medida de densidade mostrou que há uma baixa conectividade dentro da rede, dado que foi verificado apenas $26,8 \%$ do total de relações possíveis entre as oito entidades pesquisadas. Segundo Tomaél \& Marteleto (2006), baixa densidade significa que muitos relacionamentos possíveis estão ausentes na rede.

No tocante à centralidade, foram analisadas as três medidas principais, conforme Borba (2013): grau, intermediação e proximidade. De acordo com Loosemore (1998), a centralidade de grau se divide em centralidade de entrada (sinônimo de prestígio/ popularidade) e de saída (sinônimo de iniciativa - influência). Como observado na Tabela 3, as entidades centrais em termos de interações recebidas são a COGERH e o Ministério da Integração, ambas com grau de entrada correspondente a 4 ou $57,1 \%$ do total de contatos possíveis. Essas entidades apresentam a maior capacidade de receber informações sobre o projeto de integração do São Francisco na rede considerada. Elas apresentam maior acessibilidade às informações, ao contrário da Secretaria das Cidades, a qual não apresentou nenhum vínculo de entrada na rede (grau de entrada 0,0). No que diz respeito à capacidade de se relacionar com outras entidades, grau de saída, nota-se que a maior centralidade ocorre na COGERH (grau de saída 4). Ela detém $57,1 \%$ das ligações com entidades sem ligação direta, o que a coloca como maior transmissor de informação. É um transmissor para seus vizinhos e tem um maior poder na rede, dada a sua capacidade de se relacionar diretamente com um maior número de agentes. Em termos gerais, o Grau de Centralização da rede relativamente aos fluxos de saída e de entrada foi igualmente de $34,69 \%$, o que sugere um fluxo de informação desigual, concentrado em alguns agentes, enquanto outros encontram-se desinformados (Tomael \& Marteleto, 2006).

Adicionalmente, o grau de intermediação normalizado (expresso em \%) permite analisar a habilidade das entidades no que diz respeito a se conectar com os agentes importantes da rede. Assim como no grau de centralidade, a COGERH apresenta maior valor de centralidade de intermediação $(66,7 \%)$, fazendo um papel de "ponte" e sendo um elo entre várias entidades não conectadas, por onde passa grande parte do fluxo de informações geradas na rede. Várias entidades dependem da COGERH para estabelecer relações diretas com as demais, o que permite classificá-la como um potencial agente conciliador no contexto das discussões estabelecidas no âmbito do projeto, além de um estimulador de uma maior participação dos agentes. As entidades CODEVASF, Secretaria das Cidades, FAPIJA e Cáritas não possuem poder de intermediar as informações que fluem na rede (valor da medida $=0,0)$.

Em muitos casos, mais importante do que apresentar muitas ligações é estar próximo aos demais agentes da rede. Quanto a esta proximidade, a tabela traz resultados referentes à proximidade de entrada (inCloseness) e proximidade de saída (outCloseness). Considerando-se a proximidade de entrada, é possível identificar as entidades cujo recebimento de informações ocorre mais rapidamente por estarem próximas às demais. É o caso da COGERH e do Ministério da Integração. Por outro lado, o menor grau é observado na Secretaria das Cidades, corroborando o que se observa no grafo, no qual se encontra isolada das demais entidades. No que diz respeito às entidades cuja menor distância das demais favorece o envio de informações (proximidade de saída), a COGERH novamente 
TABELA 3 - Medidas de centralidade da rede de agentes do Projeto de Integração do Rio São Francisco no Ceará.

\begin{tabular}{|c|c|c|c|c|c|}
\hline \multirow[t]{3}{*}{ Métrica } & \multicolumn{5}{|c|}{ Valor } \\
\hline & \multirow[b]{2}{*}{ Entidade } & \multicolumn{2}{|c|}{ Centralidade de Saída } & \multicolumn{2}{|c|}{ Centralidade de Entrada } \\
\hline & & $\begin{array}{c}\text { Número de } \\
\text { ligações absoluto }\end{array}$ & $\begin{array}{c}\text { Número de ligações } \\
\text { normalizado (\%) }\end{array}$ & $\begin{array}{c}\text { Número de } \\
\text { ligações absoluto }\end{array}$ & $\begin{array}{c}\text { Número de ligações } \\
\text { normalizado (\%) }\end{array}$ \\
\hline \multirow{7}{*}{$\begin{array}{c}\text { Centralidade de } \\
\text { grau }\end{array}$} & Ministério da Integração & 1 & 14,3 & 4 & 57,1 \\
\hline & CODEVASF & 2 & 28,6 & 1 & 14,3 \\
\hline & SRH & 2 & 28,6 & 2 & 28,6 \\
\hline & Secretaria das Cidades & 1 & 14,3 & 0 & 0,0 \\
\hline & DNOCS & 2 & 28,6 & 2 & 28,6 \\
\hline & FAPIJA & 1 & 14,3 & 1 & 14,3 \\
\hline & Cáritas & 2 & 28,6 & 1 & 14,3 \\
\hline \multirow{6}{*}{$\begin{array}{l}\text { Centralidade de } \\
\text { intermediação }\end{array}$} & Entidade & \multicolumn{2}{|c|}{ Intermediação absoluta } & \multicolumn{2}{|c|}{ Intermediação Normalizada } \\
\hline & COGERH & \multicolumn{2}{|c|}{28,0} & \multicolumn{2}{|c|}{66,7} \\
\hline & Secretaria das Cidades & \multicolumn{2}{|c|}{0,0} & \multicolumn{2}{|c|}{0,0} \\
\hline & DNOCS & \multicolumn{2}{|r|}{2,0} & \multicolumn{2}{|c|}{4,7} \\
\hline & FAPIJA & \multicolumn{2}{|r|}{0,0} & \multicolumn{2}{|c|}{0} \\
\hline & Cáritas & \multicolumn{2}{|c|}{0,0} & \multicolumn{2}{|c|}{0,0} \\
\hline \multirow{5}{*}{$\begin{array}{c}\text { Centralidade de } \\
\text { proximidade }\end{array}$} & Entidade & \multicolumn{2}{|c|}{ Proximidade de Entrada } & \multicolumn{2}{|c|}{ Proximidade de Saída } \\
\hline & Ministério da Integração & \multicolumn{2}{|c|}{63,6} & \multicolumn{2}{|c|}{35,0} \\
\hline & CODEVASF & \multicolumn{2}{|c|}{36,8} & & 3,3 \\
\hline & $\mathrm{SRH}$ & & 53,8 & & 3,3 \\
\hline & COGERH & & 70,0 & & 3,7 \\
\hline
\end{tabular}

FONTE: Elaboração própria

apresentou um maior poder de comunicação, o que confirma a sua independência na rede, além de elevado potencial de influenciar as demais entidades. As outras entidades da rede apresentaram valores abaixo de 40, o que ressalta a sua baixa autonomia.

Com base na análise das medidas de centralidade, Borba (2013) assume três critérios para analisar a importância dos componentes da rede: i) um nó importante é aquele que está conectado a vários nós (centralidade), ii) um nó importante é aquele que está intermediando vários caminhos (intermediação), e iii) um nó importante é aquele que está próximo dos demais (proximidade). Uma análise comparativa das três medidas calculadas para cada entidade mostra que a COGERH é, sem dúvida, o componente central da rede dos principais agentes envolvidos no PISF no Ceará (Tabela 4). Ela apresenta o maior número de ligações diretas 
TABELA4 - Hierarquização das entidades envolvidas no Projeto de Integração do Rio São Francisco no Ceará, segundo as medidas de centralidade.

\begin{tabular}{|c|c|c|c|c|c|}
\hline \multirow{2}{*}{ Entidade } & \multicolumn{2}{|c|}{ Centralidade de grau } & \multirow{2}{*}{$\begin{array}{l}\text { Centralidade de } \\
\text { intermediação }\end{array}$} & \multicolumn{2}{|c|}{ Centralidade de proximidade } \\
\hline & Entrada & Saída & & Entrada & Saída \\
\hline Ministério da Integração & $1^{\mathrm{o}}$ & $3^{\circ}$ & $2^{\circ}$ & $2^{\circ}$ & $3^{\circ}$ \\
\hline CODEVASF & $3^{\circ}$ & $2^{\circ}$ & $5^{\circ}$ & $6^{\circ}$ & $4^{\circ}$ \\
\hline SRH & $2^{\circ}$ & $2^{\circ}$ & $3^{\circ}$ & $3^{\circ}$ & $4^{\circ}$ \\
\hline COGERH & $1^{\mathrm{o}}$ & $1^{\circ}$ & $1^{\mathrm{o}}$ & $1^{\mathrm{o}}$ & $1^{\mathrm{o}}$ \\
\hline Secretaria das Cidades & $4^{\mathrm{o}}$ & $3^{\circ}$ & $5^{\circ}$ & $7^{\circ}$ & $2^{\circ}$ \\
\hline DNOCS & $2^{\circ}$ & $2^{\circ}$ & $4^{\circ}$ & $4^{\mathrm{o}}$ & $2^{\circ}$ \\
\hline FAPIJA & $3^{\circ}$ & $3^{\circ}$ & $5^{\circ}$ & $5^{\circ}$ & $4^{\circ}$ \\
\hline Cáritas & $3^{\circ}$ & $2^{\circ}$ & $5^{\circ}$ & $5^{\circ}$ & $2^{\circ}$ \\
\hline
\end{tabular}

FONTE: Elaboração própria.

com as demais entidades e a maior capacidade de intermediar relações. Nota-se assim que: a) detém o maior poder de receber, transmitir, controlar e monitorar informações, b) interage mais rapidamente com as demais entidades, tanto no que se refere ao envio quanto ao recebimento de informações, e c) tem maior capacidade de captar o que acontece na rede. Ressalta-se, assim, a responsabilidade da COGERH na precisão, clareza e veracidade das informações veiculadas no âmbito do PISF.

O Ministério da Integração é a segunda entidade mais importante da rede, contudo, é superado pela Secretaria dos Recursos Hídricos na medida de centralidade de grau (saída) e por entidades como Secretaria das Cidades, DNOCS e Cáritas na medida de centralidade de proximidade (saída). Essa configuração mostra que o papel do ministério no estabelecimento de laços diretos, bem como na rapidez com que transmite as informações, merece ser fortalecido, especialmente se for considerado que é o órgão executor do projeto em nível federal.

A partir da exposição dos resultados desta seção, é observado que para o PISF há uma distinção de responsabilidades entre as entidades gestoras e executoras da obra. Sob o aspecto da inter-relação institucional relacionado com as decisões atuais e/ ou futuras para a gestão da integração, tem-se que há um alinhamento de propostas nas entidades governamentais do Estado do Ceará, porém a relação entre entidades do governo federal e entidades públicas e/ou empresariais estaduais ainda se encontra em fase de elaboração de propostas que venham a contemplar a construção de pontes para que se amplie a participação na gestão da integração pelos mais diversos agentes envolvidos. Sob esse aspecto, um dos entrevistados coloca que no processo para se construir relações institucionais, para que se tenha uma gestão participativa e horizontal, há um caminho longo a ser percorrido, pois há dificuldades até mesmo em partilhar documentos técnicos em comum entre entidades que estão sob a mesma esfera governamental.

No geral, a análise de redes mostrou um baixo nível de integração entre os agentes envolvidos. De acordo com Yi (2018) e Van Puyvelde \& Raeymaeckers (2020), a integração entre os atores 
de uma rede interfere nos processos de governança. Assim, o fato de a rede de agentes envolvidos no PISF apresentar uma baixa densidade e uma baixa centralidade reflete, de um lado, que o poder público se encontra enfraquecido no que diz respeito à capacidade de orientar os demais agentes na concretização de objetivos comuns e, de outro lado, que os agentes não governamentais não estão articulados o suficiente para formular interesses coletivos.

Hjerpe \& Nasiritousi (2015) acreditam que essa situação provavelmente leve a uma governança fragmentada, ou seja, aquela onde os processos de coordenação são difíceis, as questões relevantes não são discutidas adequadamente, há sobreposição de funções entre os atores envolvidos, os conflitos não conseguem ser minimizados. Na próxima seção são apresentados elementos que permitem uma melhor compreensão da governança da rede de agentes do PISF no Ceará.

\subsection{Os princípios de governança o Projeto de Integração do Rio São Francisco}

O sucesso da elaboração e implementação das ações inseridas no PISF requer um ambiente onde os princípios da boa governança estejam incorporados. Essa condição é reforçada pela necessidade de criação de articulação entre as entidades e entre estas e a população envolvida no projeto. A seguir é apresentada a percepção dos representantes das entidades componentes da rede de agentes do PISF e das lideranças de comunidades rurais afetadas pelo projeto no Ceará quanto à implementação dos seis princípios de boa governança.
- Princípio de voz e responsabilização

A integração do rio São Francisco apresenta-se como uma proposta mitigadora para os problemas da seca no nordeste setentrional, sendo um aspecto de concordância entre entidades e comunidades. Sobre o aspecto de se criar canais de diálogo em que se pudessem entender as demandas sociais das comunidades por parte do poder público, percebe-se, pela resposta dos entrevistados, que pouco foi realizado em termos de criação de pontes de diálogo (ex.: seminários, oficinas, palestras, câmaras setoriais, etc.).

Quanto ao atendimento dos objetivos do PISF, se esses foram atendidos, as comunidades observam que por conta de atrasos e mudanças de cronograma para execução da obra estes não foram prontamente atendidos, ficando aquém do esperado se for utilizado o critério dos objetivos iniciais definidos no relatório técnico EIA-RIMA de 2004, pois a obra ainda está em execução em alguns trechos. Destaca-se como ponto de exemplo sobre a alteração de objetivos da integração - conforme observado nessa pesquisa - a retirada do município de Ipaumirim-CE como beneficiário direto das águas da integração para as suas comunidades listadas no referido relatório. Já para as entidades executoras e gestoras, os objetivos iniciais planejados para a integração estão sendo plenamente atendidos, não havendo qualquer tipo de alteração. Percebe-se então que o diálogo não se fez presente entre o poder público e as comunidades, não se construíram canais mais horizontais que auxiliassem a participação popular, dando o direito de vez e voz nas ações decisórias para o PISF. 
$\mathrm{Na}$ opinião dos representantes das entidades, algumas ações pontuais de participação popular das entidades públicas foram realizadas no âmbito do PISF. A maior dificuldade observada nos avanços na evolução de canais de comunicação que garantissem uma participação popular nas decisões do projeto se deu por conta de atrasos nas obras e por ter havido uma instabilidade institucional entre quem iria administrar a gestão da integração após a entrega das obras. Para o Estado do Ceará, há avanços na gestão hídrica em seus comitês de bacias hidrográficas - total de 12 -, porém, avanços no diálogo entre $\mathrm{CBH}$ cearenses e órgãos federais responsáveis pela integração do Rio São Francisco ainda se encontram em fase inicial. Desta forma, houve baixa implementação do princípio de voz e responsabilização no processo de decisões do PISF, bem como também pouco se buscou entender quais seriam as reais demandas sociais para pós-entrega da obra.

Os representantes das comunidades rurais visitadas observam que as reuniões coordenadas pelos órgãos federais de gestão da integração do Rio São Francisco (M.I. e CODEVASF) com as comunidades rurais beneficiárias diretas da integração ocorreu tardiamente. As reuniões foram anuais e, apesar de ter acontecido uma considerável mobilização em termos de atores sociais interessados pelo PISF, não foi dada oportunidade de diálogo entre o poder público e os representantes das comunidades. Sendo assim, as reuniões foram mais de esclarecimento técnico do que de entendimento de suas demandas sociais.

Alguns entrevistados também observam a ausência de divulgação para o dia das reuniões e muitos deles participaram de forma casual, sem o referido entendimento da importância desses encontros. Em algumas falas, alguns presidentes de associações comunitárias rurais sequer sabiam que sua comunidade iria ser beneficiária de pelo menos 04 ha de área irrigada por família, águas advindas do PISF.

\section{- Princípio de estabilidade política}

O movimento de articulação governamental relacionado às ações do PISF ocorre com maior grau de interação entre as instituições do que entre instituições e comunidades. Este aspecto denota a ineficiência por parte do poder público em procurar buscar parcerias com as comunidades no sentido de promover uma gestão que venha a se tornar mais eficiente sob o aspecto da construção de estratégias de ações que venham a promover o desenvolvimento e a sustentabilidade ambiental para o PISF.

No que concerne à existência de conflitos políticos, as opiniões dos entrevistados estão divididas, pois no processo de implementação das ações de gestão para as obras do PISF houve discussões de viés político, principalmente na fase final - últimos dois anos -, sobre qual órgão federal assumiria a gestão técnica e gerencial da integração, sendo escolhida a Companhia de Desenvolvimento dos Vales do São Francisco e do Parnaíba (CODEVASF). Na fala de um entrevistado, não houve um diálogo prévio entre as instituições de forma a tentar equalizar a decisão da escolha da CODEVASF, sendo algo conflituoso entre DNOCS - órgão público histórico de mitigação dos problemas da seca - e Ministério da Integração que nomeou a CODEVASF para as atribuições gerenciais do PISF.

As entidades e as comunidades também percebem que, por conta da ausência de construção de canais de diálogo entre sociedade civil e poder público, há uma reduzida participação popular nos 
processos de decisão de interesse público, estando os atores sociais no papel de meros recebedores das decisões políticas implementadas de forma vertical. $\mathrm{Na}$ fala de um dos entrevistados, decisões de base mais técnica de execução da obra realmente não necessitam passar pelo crivo de se ter que formalizar palestras, fóruns, seminários etc., como instrumentos de decisão. Porém, quando o caráter de decisão das ações para a integração passa a ter um caráter de discussão dos possíveis impactos, sejam eles sociais e/ou ambientais, aí sim necessita-se construir meios em que se possa horizontalizar a participação de todas as partes interessadas nas decisões públicas.

Os representantes das entidades colocam que as articulações políticas para o início da obra de integração foram fundamentais para o andamento e o avanço do PISF. Porém, alguns problemas institucionais surgiram ao longo desse processo. Em algum momento foi identificado, na fala de um dos entrevistados, que até uns três anos antes da pesquisa não havia sido decidido quem iria gerir a obra pós sua entrega. Outro fato relevante está relacionado ao processo de impeachment da Presidente Dilma Rousseff. Até aquele momento e desde o ano de 2012 havia um movimento dos órgãos públicos em se começar a investigar e a dialogar com a sociedade civil suas reais demandas socioeconômicas, principalmente para os estados receptores, sendo que no momento da pesquisa, no governo Temer, não mais há esse tipo de ação pelos órgãos federais de gestão da integração do Rio São Francisco, pois houve uma quebra nas estruturas e nos canais de diálogos. $\mathrm{O}$ que existe são levantamentos de questões de ordem técnica e operacional para a finalização da obra de integração.

Para a população rural, a instabilidade política é percebida como sendo algo negativo, que atrapalha as futuras redes institucionais de gestão da integração. Nesse sentido, os entrevistados observam que na conjuntura política corrente haverá poucos avanços no diálogo entre sociedade civil e poder público.

\section{- Princípio de eficácia governamental}

Para as obras de execução do PISF, tanto as instituições como as comunidades percebem que são executadas por gestores com qualificação técnica suficiente para tal fim, sendo também observada pelos entrevistados a dedicação dos gestores técnicos, sendo um aspecto positivo. Porém, é percebido pelas entidades e pelas comunidades que houve e ainda há insuficiência no número de profissionais, tanto para execução da obra como para sua futura gestão.

Sobre o aspecto dos recursos financeiros disponíveis, as entidades e as comunidades enxergam que há recursos suficientes. Porém, é percebido pelos entrevistados que parte dos recursos financeiros para execução da obra poderia também ser destinada para ações voltadas para estratégias de construção de canais de diálogo entre sociedade civil e poder público. Nota-se, pela fala dos entrevistados, tanto das entidades como das comunidades, que muito se anseia por melhorar o relacionamento do poder público com a sociedade, para que se possa ter, na gestão futura da integração, propostas e ações que venham a contemplar o equilíbrio social e ambiental das mais diversas partes interessadas.

A partir da fala dos representantes das entidades, percebe-se que o governo federal teve o cuidado de trabalhar sempre com especialistas em obras hidráulicas, mas em número insuficiente. Partindo para os recursos financeiros, houve durante um tempo uma certa regularidade nos repasses, mas, 
por problemas operacionais e de gestão, foi necessário se requerer um maior montante de recursos financeiros para finalização da obra. Sob a influência política relacionada ao PISF, foi verificado que nenhum entrevistado identifica ações na proposta da integração do Rio São Francisco que venham a trazer benefícios a partidos políticos. Os benefícios, observam os entrevistados, serão diretamente para as comunidades e populações do entorno da integração do São Francisco, sendo uma água que garantirá o uso doméstico por água potável.

Segundo os representantes da população rural, o melhor avanço no sentido de eficácia governamental se deu na implantação da Vila Produtiva Rural do Retiro no município de Penaforte-CE, onde as famílias reassentadas tiveram a oportunidade de colocar as suas necessidades no projeto de implementação da vila, estando essa com infraestrutura para o funcionamento de escola primária, posto de saúde, quadra de esportes e cerca de 04 ha de terra para ser cultivado por cada família. As dificuldades relatadas na Vila Produtiva do Retiro foram: o não funcionamento da escola e do posto de saúde por falta de profissionais de educação e saúde e a necessidade de se obter a Declaração de Aptidão ao PRONAF (DAP) para, a partir desse documento, se poder retirar empréstimo bancário para financiar o custeio de implementação de sistemas de irrigação para as áreas cultiváveis. Para as demais comunidades, planos estratégicos de desenvolvimento não foram sequer citados, sendo então projetos e cenários que serão avaliados e construídos não se sabe se num futuro próximo.

- Princípio de qualidade regulatória

Nas ações do PISF, as comunidades e entidades percebem que há um baixo nível de planejamento estratégico e uma baixa percepção de que realmente o PISF venha a garantir a promoção de melhorias no desenvolvimento social e local dos municípios por onde passaram os canais da integração. Essa baixa credibilidade se dá por conta dos prazos não cumpridos para o término da obra.

Por algumas vezes a obra teve que ser interrompida por problemas nas licitações das empresas executoras (medidas e ações judiciais), bem como algumas empresas declararam falência. Então, questiona-se o efetivo papel do poder público como fiscalizador dos seus parceiros executores da obra. Porém, os entrevistados acreditam que a integração do Rio São Francisco garantirá principalmente a regularidade da disponibilidade de águas para o semiárido setentrional, embora alguns questionamentos sejam levantados por parte dos entrevistados, como: a água será distribuída? Será de forma mais corporativa ou social? Será respeitada a legislação ambiental?

Quanto à existência de uma representação política que garanta uma melhor qualidade regulatória para o PISF, foi percebido que esse critério está aquém do esperado, não havendo principalmente uma liderança política que busque garantir o atendimento das demandas sociais e ambientais para as esferas local e global para a proposta da integração.

Os representantes das entidades colocam que ações de qualidade regulatória por parte do poder público foram pontuais e descontínuas. $\mathrm{O}$ entendimento das reais necessidades sociais, econômicas e ambientais das comunidades rurais e municípios que serão atendidos de forma direta pelo PISF está em fase ainda de campo e de reconhecimento de áreas. Um ponto importante colocado pelos entrevistados é que após a entrega da obra é que se procurará criar uma legislação específica que regule o direito de 
uso das águas da integração para os mais variados atores sociais e segmentos empresariais. Para os entrevistados, no decorrer desse tempo, desde quando se iniciou a obra em meados do ano de 2004, já era para existir uma legislação capaz de garantir uma maior transparência e acessibilidade relacionadas ao uso das águas da integração do São Francisco para os mais diversos usos e demandas.

\section{- Princípio de Estado de Direito}

A justiça social para a integração é melhor percebida pelas entidades do que pelas comunidades, o que, mais uma vez, reflete a ausência de diálogo entre poder público e sociedade civil para um melhor esclarecimento dos critérios norteadores da integração que melhor garantam a justiça social. Assim, a confiabilidade nas ações relacionadas ao PISF é vista como algo que ainda não contribui para o estado de direito, sendo necessárias ações mais eficazes do poder público nesse sentido.

As entidades e comunidades (não na sua totalidade) enxergam que há sim imparcialidade nas ações nesse sentido para o PISF. Na fala de um dos entrevistados de uma entidade, as ações da integração do rio São Francisco não fazem qualquer tipo de distinção de classe relacionado à garantia para a segurança hídrica, sendo as águas da integração vistas como uma água social, estando mais fortemente relacionada ao abastecimento humano do que seu uso para qualquer fim comercial ou empresarial.

Outro aspecto avaliado foi a legitimidade da integração para a garantia do estado de direito, para as entidades, e qual é a base fundamental na busca do equilíbrio social das águas do PISF para que não haja principalmente conflitos, onde todas as partes interessadas venham a ter garantidos seus direitos, respeitando seus limites. Já as comunidades não têm a plena certeza da legitimidade da integração em atendimento aos seus anseios sociais e econômicos de acesso à água. Assim, se nota a falta de esclarecimento por parte do poder público sobre os benefícios sociais e econômicos e até mesmo ambientais que a integração do rio São Francisco possa trazer para as comunidades beneficiadas.

Com relação ao estado de direito, esse foi garantido pelas entidades pesquisadas, sendo respeitada a legislação vigente para o PISF. Destaca-se, conforme relatado pelos entrevistados, o cumprimento, por parte do poder público, do decreto 8.207/2014 (Sistema de Gestão do PISF com as Bacias Hidrográficas do Nordeste Setentrional).

Sob o aspecto da garantia das águas da integração do Rio São Francisco para as comunidades rurais do semiárido, atendidas de forma direta ou indireta, tem-se a percepção de algo que é positivo, pois grande parte deles observa que a garantia do direito a água será ampliada com a implementação de áreas irrigadas, deixando a agricultura de ser dependente somente da quadra invernosa.

\section{- Princípio de Controle da Corrupção}

A sociedade brasileira tem buscado cada vez mais eficiência no controle dos gastos públicos. $\mathrm{O}$ controle da corrupção para uma obra de integração de rios é de fundamental importância, pois o montante de recursos financeiros para a execução das obras de construção civil - rede de canais - e hidráulicas - estações de bombeamento, estações elétricas, etc. - chega à cifra de bilhões de reais e vários são os gerentes e empresas que têm acesso ao montante de verba destinado pelo governo federal.

Para a análise do controle da corrupção, foi questionado se as entidades e/ou comunidades tinham como identificar a existência de corrupção 
nas ações locais para o PISF. Era esperado que pelo menos as entidades tivessem ferramentas mais eficazes para identificar desvios de verba pública para a obra, porém, é algo inexistente. Na fala de alguns entrevistados, foi relatado desvio de verba de forma indireta por meio de uso inadequado de material da obra para construção dos canais (ferro, cimento, brita, etc.). Porém, ao serem questionados sobre a gestão interna para controle da corrupção (transparência, responsabilidade governamental, institucional, etc.), as entidades demonstram que há sim em seu escopo gerencial medidas que impedem atos de desvio de verbas públicas ou de benesses para grupos empresariais e/ou políticos. Para as comunidades, este aspecto de controle interno para se evitar corrupção é visto como algo externo, que é percebido quando identificada principalmente a venda de materiais de construção que eram da obra nos comércios locais.

Ao serem questionados sobre ganhos particulares por meio das obras do PISF, as entidades discordam sobre esse aspecto. Já os entrevistados das comunidades ficaram divididos sobre esse assunto. $\mathrm{Na}$ fala de um entrevistado (comunidade), o mesmo coloca que os ganhos particulares relacionados a algum aspecto de corrupção estão mais fortemente ligados a alguns comerciantes que compraram materiais de construção desviados da obra (mais barato) e que colocaram no comércio local para a venda - questão mais evidenciada na pesquisa sobre o critério da corrupção local.

As comunidades e entidades entendem que se faz necessário construir mecanismos de fiscalização mais eficientes para que se possam denunciar desvios de recursos financeiros. As entidades e comunidades estão alinhadas no apoio de forma positiva a quaisquer tipos de ações políticas que tenham por princípio o controle da corrupção. Para o aspecto de ganhos particulares, as entidades gestoras diretas da integração não observam tanto tal comportamento. Porém, é notório por parte de todos os entrevistados, tanto das entidades como das comunidades, que a corrupção foi algo negativo para a integração do rio São Francisco como um todo.

Com relação à execução do cronograma da obra, foi percebido pelos entrevistados que houve uma série de atrasos por conta de denúncias de corrupção ocorrente nas empreiteiras envolvidas, que acabaram por se retirar da obra, havendo a necessidade do poder público realizar novos processos de licitação. As empreiteiras foram investigadas pela operação "Vidas Secas", braço da operação "Lava Jato", realizada pela Polícia Federal em dezembro de 2015. O consórcio, formado pelas empreiteiras OAS, Galvão Engenharia, Barbosa Melo e Coesa, foi investigado por desvio de $\mathrm{R} \$ 200$ milhões dos recursos financeiros da obra por meio dos doleiros Alberto Youssef e Adir Assad. Por conta das investigações, o consócio foi dissolvido e a obra passou por novo processo de licitação, atrasando o cronograma de execução em um ano e meio. Um fator de destaque, conforme relatado pelos entrevistados, é que se gerou em torno das obras da integração do rio São Francisco toda uma cadeia econômica relacionada à prestação de serviços nos municípios próximos. Por conta do consórcio ter sido dissolvido pelas empresas envolvidas em corrupção, houve assim uma série de calotes por parte das empresas investigadas nos setores de hotelaria e de restaurantes que prestavam serviços para o consórcio, bem como um aumento nos níveis de desemprego.

Os entrevistados das comunidades rurais observam o controle da corrupção como algo que trará uma amplitude na moralização das políticas 
públicas de nosso país. Alguns relatos foram importantes sob esse aspecto. Um deles refere que durante o prazo de execução da obra, mais precisamente no período de concretagem dos canais, havia um dia na semana em que parte do cimento que era para ser utilizado na obra acabava por ser desviado e comercializado no comércio local, sendo a saca de cimento comercializada a um preço $50 \%$ menor do que seu valor. Após a operação da Polícia Federal, em que houve a saída do grupo de empreiteiras investigadas por corrupção, essa situação não foi mais observada. Alguns entrevistados também relatam que para a obra do PISF não faltou dinheiro e sim o que faltou foram métodos de fiscalização que fossem mais eficientes.

Diante dos pontos expostos, percebe-se que para a integração do Rio São Francisco há um longo caminho a se percorrer para que seja efetivamente concluída a obra, não somente sobre uma visão técnica relacionada à simples construção de uma rede de canais e demais instalações hidráulicas, mas também sobre uma visão sistêmica, em que estejam efetivamente inclusos nas políticas de gestão das águas da integração os princípios que norteiam a boa governança, para que haja um equilíbrio efetivo entre homem e meio ambiente, sendo garantido o acesso à água de forma justa para os 12 milhões de nordestinos que, a princípio, a obra visa contemplar.

\section{Considerações finais}

A integração do Rio São Francisco tornou-se na última década uma obra de relevância nacional, com gastos públicos consideráveis em várias ações relacionadas com a execução somente da obra. Observa-se, porém, que foram poucos os avanços sobre a construção de uma gestão participativa pautada na boa governança.

O estudo confirmou que o Projeto de Integração do Rio São Francisco no Ceará é gerido por uma rede de agentes pouco conectados, rede esta que favorece uma governança fragmentada, com implicações negativas sobre a concretização dos objetivos propostos no projeto e sobre a minimização dos conflitos que tendem a se acentuar após a finalização da obra e o início da distribuição da água. Os diálogos entre as entidades envolvidas no PISF e entre estas e a sociedade civil encontram-se em fase inicial. A ausência de pertencimento e de conexão entre as entidades se dá principalmente pelo fato de a gestão do PISF estar centralizada, em nível nacional, apenas na entidade CODEVASF, ou seja, não há uma gestão colaborativa em que o conhecimento/informação seja repartido. Como agravante, a CODEVASF não apresenta forte integração com os agentes da rede.

A fragilidade na estrutura de governança que perpassa o projeto foi sentida em diferentes nuances dos princípios de uma boa governança. Observa-se, por exemplo, a falta de estabilidade política por parte do poder público. Nesse aspecto, as reuniões entre entidades e comunidades apresentaram-se de forma espaçada e sem haver o momento para apresentação da posição dos representantes sociais das comunidades. Há também alguns gargalos que precisam ser debatidos entre poder público e sociedade civil para que não haja conflitos futuros, tais como: como será a cobrança pelo uso da água? Qual a relação da entidade CODEVASF com os órgãos públicos de gestão hídrica e com os $\mathrm{CBH}$ de cada estado atendido pela integração? Qual o papel do governo como fomentador para o diálogo entre instituições e sociedade civil no processo de 
governança para a promoção da sustentabilidade ambiental do PISF?

A baixa conexão entre as entidades que formam a rede do PISF e a fragilidade nos princípios de governança podem se constituir fatores limitantes para o sucesso do projeto, pois cria a possibilidade de sobreposição de funções, dificuldades no estabelecimento de prioridades e competências e comportamentos que podem negligenciar as demandas sociais e oportunidades para a solução de conflitos, sendo este um dos pontos de grande vulnerabilidade dessa intervenção. Por fim, com as devidas ressalvas, as conclusões obtidas na análise do PISF podem ser um alerta para um contexto mais amplo, sendo importante pensar a fragilidade das ligações interinstitucionais e entre a sociedade como um uma característica comum na gestão dos recursos hídricos e demais políticas voltadas para a convivência com o semiárido.

\section{Agradecimentos}

Pesquisa financiada pelo Conselho Nacional de Desenvolvimento Científico - Edital CNPq/ MCTI No 25/2015.

\section{Referências}

Barbosa, A. M. S.; Martins Jr., A. Redes e capital social: usos possíveis e eventuais limitações enquanto categorias sociológicas. Contemporânea: Revista de Sociologia da UFSCar, [s.1.], 8(1), 239-264, 2018.

Bodin, Ö.; Crona, B. L. The role of social networks in natural resources governance: What relational patterns make a difference? Global Environmental Change, [s.1.], 19(3), 366-374, 2009.

Borba, E. M. Medidas de Centralidade em Grafos e aplicações em rede de dados. Porto Alegre, Dissertação (Mestrado) - Programa de Pós-Graduação em Matemática Aplicada (PPGMAp) da Universidade Federal do Rio Grande do Sul, 2013.

Braun, B. Environmental Issues: inventive life. Progress in Human Geography, [s.1.], 32(5), 667-679, 2008.

Brito, F. B. Conflitos pelo acesso e uso da água: integração do Rio São Francisco com a Paraíba (Eixo Leste). Porto Alegre, Tese (Doutorado) - Universidade Federal do Rio Grande do Sul, 2013.

Campos, J. N. B. Paradigms and Public Policies on Drought in Northeast Brazil: A Historical Perspective. Environmental Management, 1(12), 2015.
Chaffin, B. C.; Garmestani, A. S.; Gosnell, H.; Craig, R. $\mathrm{K}$. Institutional networks and adaptive water governance in the Klamath River Basin, USA. Environmental Science \& Policy, 57, 112-121, 2016.

Delgado, A. B.; Triana, D. R.; Sayago, D. A. V. A perspectiva relacional das redes sociais no contexto das políticas públicas participativas. Brasília: Centro de Desenvolvimento Sustentável - UnB, 2013.

Ferreira, J. G. A transposição das águas da bacia do rio São Francisco no contexto da resposta à seca do Nordeste. Anais do Encontro Nacional da Associação Nacional de Pós-Graduação e Pesquisa em Ambiente e Sociedade (ANPPAS), 2017.

Galvão, M. L. de M.; Santos, M. A. dos; Silva, N. F. da; Silva, V. P. da. Connections between Wind Energy, Poverty and Social Sustainability in Brazil's Semiarid. Sustainability, 12(3), 864, 2020.

Garcia, L. P. Governança para emancipação: uma proposta para o enfrentamento intersetorial de iniquidades. Florianópolis, Dissertação (Mestrado Profissional em Administração) - Universidade do Estado de Santa Catarina, 2014. 
Gomides, J. E.; Silva, A. C. O surgimento da expressão "governance", governança e governança ambiental: um resgate teórico. Revista de Ciências Gerenciais, 13(18), 177-194, 2009.

Goria, A.; Sgobbi, A.; Homeyer, I. von. Governance for the Environment: A comparative Analysis of Environmental Policy Integration. Northampton-UK: Edward Elgar Publishing Limited, 2010.

Guimarães Jr., J. A. Reforma hídrica do Nordeste como alternativa à transposição do rio São Francisco. Cadernos do CEAS: Revista Crítica de Humanidades, 227, 80-88, 2016.

Hatala, J. P. Social Analysis in Human Resource Development: A New Methodology. Human Resource Development Review, [s.1.], 5(1), 49-71, 2006.

Higgins, S. S.; Ribeiro, A. C. A. Análise de redes em Ciências Sociais. Brasília: ENAP - Fundação Nacional de Administração Pública, 2018.

Hjerpe, M.; Nasiritousi, N. Views on alternative forums for effectively tackling climate change. Nature Climate Change, 5(9), 864-867, 2015.

Howlett, M.; Ramesh, M.; Perl, A. Política Pública: seus ciclos e subsistemas, uma abordagem integral. São Paulo: Elsevier, 2013.

Kapucu, N.; Hu, Q. Network Governance: Concepts, Theories, and Applications. New York: Routledge, 2020.

Lemieux, V.; Ouimet, M. Análise estrutural das redes sociais. Lisboa: Instituto Piaget, 2008. 116 p.

Lima, P. V. P. S.; Mendes, C. M.; Rocha, L. A.; Oliveira, M. R. R. No rastro da vulnerabilidade às secas: uma análise da produção de grãos no semiárido brasileiro. Revista Eletrônica Documento Monumento, 19(1), 183-193, 2016.

Liu, W. C.; Huang, L. C.; Liu, C. W. J.; Jordán, F. A simple approach for quantifying node centrality in signed and directed social networks. Applied Network Science, 5(1), 1-26, 2020.

Loosemore, M. Social network analysis: using a quantitative tool within an interpretative context to explore the management of construction crises. Engineering, Construction and Architectural Management, [s.1.], 5(4), 315-326, 1998.
Loureiro, M. R.; Teixeira, M. A. C.; Ferreira, A. M. Desenvolvendo capacidades estatais: conflitos e articulação de interesses no Projeto de Integração do Rio São Francisco. Desenvolvimento em Questão, 12(28), 5-36, 2014.

Maciel, R. H. de O.; Santos, J. B. F. dos; Matos, T. G. R.; Maia, L. M.; Fontenelle, M. F. Redes sociais e capital social na formação de redes socioprodutivas: estudo em uma feira de confecções de Fortaleza. Cadernos de Psicologia Social do Trabalho, [s.1.], 17(1), 33-47, 2014.

Marengo, J. A.; Alves, L. M.; Alvala, R.; Cunha, A. P.; Brito, S.; Moraes, O. L Climatic characteristics of the 2010-2016 drought in the semiarid Northeast Brazil region. Anais da Academia Brasileira de Ciências, 90(2), 1973-1985, 2018.

Meinzen-Dick, R. Beyond panaceas in water institutions. Proceedings of the National Academy of Sciences, [s.1.], 104(39), 15200-15205, 2007.

Mertens, F.; Saint-Charles, J.; Mergler, D.; Passos, C. J.; Lucotte, M. A network approach for analysing and promoting equity in participatory Ecohealth research. Ecohealth, [s.1.], 2, 116-123, 2005.

Morais, E. A.; Carvalho, J. S. F. de; Almeida, P. L. R. de; Alcântara, H. M. de; Costa Medeiros, P. da. Conflitos de acesso e uso da água na bacia do rio Paraíba após operação do projeto de integração do rio São Francisco/Conflicts of access and use of water in the Paraíba river basin after operation of the São Francisco river integration project. Brazilian Journal of Development, 6(1), 5098-5108, 2020.

Nasuti, S.; Eiró, F.; Lindoso, D. Os desafios da agricultura no Semiárido Brasileiro. Sustentabilidade em Debate, 4(2), 276-298, 2013.

Obermaier, M.; Rosa, L. P. Mudança climática e adaptação no Brasil: uma análise crítica. Estudos Avançados, 27(78), 155-176. 2013.

Pretty, J. Social Capital and the Collective Management of Resources. Science, [s.1.], 302, 1912-1913, 12 dez. 2003. Disponível em: <www.sciencemag.org>.

Procopiuck, M.; Frey, K. Redes de políticas públicas e de governança e sua análise a partir da websphere analysis. Rev. Sociol. Polit., 17(34), 63-83, 2009. 
Rocha, J. C. S da; Khoury, L. E. C; Damasceno, Â. P. D. Direito das águas-trajetória legal, conflitos e participação social. Revista de Direito Sanitário, [s.1.], 18(3), 143-166, 2018.

Rogers, P.; Jalal, K. F.; Boyd, J. A. An Introduction to Sustainable Development. Cambridge: The Continuing Education Division, Harvard University and Glen Educational Foundation, 2006.

Scholes, R. J. The Future of Semi-Arid Regions: A Weak Fabric Unravels. Climate, 8(3), 43, 2020.

Schultz-Jones, B. Examining information behavior through social networks. Journal of Documentation, [s.1.], 65(4), 592-631, 2009.

Scott, J. Social network analysis. 3. ed. Londres: Sage Publications, 2013.

Silva, E. N. Projeto de integração do Rio São Francisco: avaliação da governança e do capital social como instrumentos para a promoção de uma gestão pública sustentável. Fortaleza, Tese (Doutorado em Desenvolvimento e Meio Ambiente) - Universidade Federal do Ceará, 2018.
Serrão, M.; Almeida, A.; Carestiato, A. Sustentabilidade: uma questão de todos nós. São Paulo: Editora Senac São Paulo, 2020.

Souza, D. L.; Castro, C. C.; Antonialli, F.; Souza Corrêa, R. D. de. Redes na Educação a Distância: uma análise estrutural do sistema UAB em Minas Gerais. Pretexto, 15, 84-98, 2014.

Tomaél, M. I.; Marteleto, R. M. Redes sociais: posições dos atores no fluxo da informação. Revista Eletrônica de Biblioteconomia e Ciência da Informação, [s.1.], 11(1), 75-91, 2006.

Van Puyvelde, S.; Raeymaeckers, P. The governance of public-nonprofit service networks: Four propositions. Nonprofit and Voluntary Sector Quarterly, p. 0899764020913113, 2020 .

Wellman, B.; Berkowitz, S. D. (Eds.). Social structures: A network approach. Cambridge, England: Cambridge University Press, 1988.

Yi, H. Network structure and governance performance: What makes a difference? Public Administration Review, 78(2), 195-205, 2018. 